\title{
ON EDGE $H$-IRREGULARITY STRENGTHS OF SOME GRAPHS
}

\author{
Muhammad NaEem $^{1}$ \\ Department of Mathematics, The University of Lahore \\ Pakpattan Campus, 57400, Pakistan \\ e-mail: naeempkn@gmail.com \\ Muhammad Kamran Siddiqui \\ Department of Mathematics, COMSATS University Islamabad \\ Sahiwal Campus, 57000, Pakistan \\ e-mail: kamransiddiqui75@gmail.com \\ Martin BaČa, Andrea Semaničová-FeñovČíková \\ Department of Applied Mathematics and Informatics \\ Technical University, Košice, Slovakia \\ e-mail: martin.baca@tuke.sk, andrea.fenovcikova@tuke.sk
}

AND

FARAHA ASHRAF

Abdus Salam School of Mathematical Sciences

GC University, Lahore, Pakistan

e-mail: faraha27@gmail.com

\begin{abstract}
For a graph $G$ an edge-covering of $G$ is a family of subgraphs $H_{1}, H_{2}, \ldots$, $H_{t}$ such that each edge of $E(G)$ belongs to at least one of the subgraphs $H_{i}$, $i=1,2, \ldots, t$. In this case we say that $G$ admits an $\left(H_{1}, H_{2}, \ldots, H_{t}\right)$ - $(e d g e)$ covering. An $H$-covering of graph $G$ is an $\left(H_{1}, H_{2}, \ldots, H_{t}\right)$-(edge) covering in which every subgraph $H_{i}$ is isomorphic to a given graph $H$.

Let $G$ be a graph admitting $H$-covering. An edge $k$-labeling $\alpha: E(G) \rightarrow$ $\{1,2, \ldots, k\}$ is called an $H$-irregular edge $k$-labeling of the graph $G$ if for every two different subgraphs $H^{\prime}$ and $H^{\prime \prime}$ isomorphic to $H$ their weights
\end{abstract}

\footnotetext{
${ }^{1}$ Corresponding author.
} 
$w t_{\alpha}\left(H^{\prime}\right)$ and $w t_{\alpha}\left(H^{\prime \prime}\right)$ are distinct. The weight of a subgraph $H$ under an edge $k$-labeling $\alpha$ is the sum of labels of edges belonging to $H$. The edge $H$-irregularity strength of a graph $G$, denoted by ehs $(G, H)$, is the smallest integer $k$ such that $G$ has an $H$-irregular edge $k$-labeling.

In this paper we determine the exact values of ehs $(G, H)$ for prisms, antiprisms, triangular ladders, diagonal ladders, wheels and gear graphs. Moreover the subgraph $H$ is isomorphic to only $C_{4}, C_{3}$ and $K_{4}$.

Keywords: $H$-irregular edge labeling, edge $H$-irregularity strength, prism, antiprism, triangular ladder, diagonal ladder, wheel, gear graph.

2010 Mathematics Subject Classification: 05C78, 05C70.

\section{REFERENCES}

[1] A. Ahmad, O.B.S. Al-Mushayt and M. Bača, On edge irregularity strength of graphs, Appl. Math. Comput. 243 (2014) 607-610. https://doi.org/10.1016/j.amc.2014.06.028 
[2] M. Aigner and E. Triesch, Irregular assignments of trees and forests, SIAM J. Discrete Math. 3 (1990) 439-449. https://doi.org/10.1137/0403038

[3] D. Amar and O. Togni, Irregularity strength of trees, Discrete Math. 190 (1998) 15-38. https://doi.org/10.1016/S0012-365X(98)00112-5

[4] F. Ashraf, M. Bača, Z. Kimáková and A. Semaničová-Feňovčíková, On vertex and edge $H$-irregularity strengths of graphs, Discrete Math. Algorithms Appl. 8 (2016) 1650070 . https://doi.org/10.1142/S1793830916500701

[5] M. Anholcer and C. Palmer, Irregular labellings of circulant graphs, Discrete Math. 312 (2012) 3461-3466. https://doi.org/10.1016/j.disc.2012.06.017

[6] T. Bohman and D. Kravitz, On the irregularity strength of trees, J. Graph Theory 45 (2004) 241-254. https://doi.org/10.1002/jgt.10158

[7] G. Chartrand, M.S. Jacobson, J. Lehel, O.R. Oellermann, S. Ruiz and F. Saba, Irregular networks, Congr. Numer. 64 (1988) 187-192.

[8] R.J. Faudree and J. Lehel, Bound on the irregularity strength of regular graphs, Colloq. Math. Soc. János Bolyai, 52, Combinatorics, Eger North Holland, Amsterdam (1987) 247-256.

[9] A. Frieze, R.J. Gould, M. Karoński and F. Pfender, On graph irregularity strength, J. Graph Theory 41 (2002) 120-137. https://doi.org/10.1002/jgt.10056

[10] M. Imran, M. Naeem and A.Q. Baig, On vertex covering number of rotationallysymmetric graphs, Util. Math. 97 (2015) 295-307.

[11] M. Kalkowski, M. Karoński and F. Pfender, A new upper bound for the irregularity strength of graphs, SIAM J. Discrete Math. 25 (2011) 1319-1321. https://doi.org/10.1137/090774112

[12] P. Majerski and J. Przybyło, On the irregularity strength of dense graphs, SIAM J. Discrete Math. 28 (2014) 197-205. https://doi.org/10.1137/120886650

[13] T. Nierhoff, A tight bound on the irregularity strength of graphs, SIAM J. Discrete Math. 13 (2000) 313-323. https://doi.org/10.1137/S0895480196314291

[14] J. Przybyło, Irregularity strength of regular graphs, Electron. J. Combin. 15 (2008) \#R82. https://doi.org/10.37236/806

Received 2 November 2018 Revised 25 March 2019 Accepted 25 March 2019 